\title{
DEMENTIA PRÆCOX.
}

BY GERSHOM H. HILL, M. D.,

Independence, Iowa.

Our professional fathers in this specialty contended that deranged persons are not possessed with devils, nor bewitched, nor mad, but that they are suffering from disease, and, consequently, need kind care and skillful medical treatment. They are patients and require the advantages of a hospital. Ray, Kirkbride, Van Dusen, Ranney, Gray and Godding were pioneers in this work. Their contention for buildings sufficient in size, suitable in arrangement and good in quality, was successful. Although how to secure proper care for all the chronic insane is still a vexed question in most States of our Union, we now have wellequipped hospitals for the treatment of the acute insane, and competent physicians and trained nurses to minister to them. In most States sufficient funds are provided to carry on this work. During the time that good provision was being secured for the insane, general hospitals multiplied. Physicians have learned how to use the knife and surgeons how to practice medicine. During the last quarter of a century the time required for a medical education has doubled and the facilities for learning the science and the art of medicine are not to be compared with those of olden times. Furthermore, we now have opportunities for studying insanity in a more scientific manner. Since less of our time is taken up in enlightening law-makers and in superintending the construction of buildings, we can with great advantage to our patients, study the causes of insanity, observe the clinical symptoms of the men and women placed in our hands for treatment, make each individual a separate object for research, not only while he is an occupant of the wards of the hospital, but as far as possible from the beginning to the end of his life.

It has always been my purpose to make a post-mortem exam- 
ination of the brain and other organs of every patient who dies in the hospital for the insane with which I am connected. For many years we have succeeded in doing this; it has only been a few years, however, since I have succeeded in getting a sufficient number of physicians on the medical staff of the hospital to enable us to do good, systematic work in our pathological laboratory, and at the same time study mental derangement in the wards of the hospital in a systematic manner. If the physician, who gives the patient a thorough mental and physical examination at the time he is admitted into the hospital, does not already know the family history of that patient, the extent of his schooling, his social, his religious and business life, together with the more prominent characteristics of his nature up to the day of his reception into the hospital, these facts are secured, by correspondence or otherwise, as soon as possible; then an abstract of the history of each patient is read, at an early day, in a meeting of the medical staff of the hospital, and the etiology, the diagnosis and the prognosis in each case are determined, if possible. In order to know the results of treatment in the hospital, it is desirable, as far as possible, to keep track of all patients after they are discharged.

In undertaking the scientific study of insanity, we are using Kraepelin's methods, and his classification of the different forms of mental derangement as a guide. The understanding is, of course, that the nomenclature used, and the grouping of cases agreed upon, is not final nor surely correct, but only hypothetical and tentative. At the meeting of the Association last year, Dr. Cowles, in a broad and masterly manner, made a comparison of the forms of insanity as suggested by Kraepelin with those which have been most commonly recognized by alienists. Instead of studying insanity chiefly from an etiological or from a symptomatic standpoint, Kraepelin proceeds by keeping constantly in mind and in the foreground the prognosis in each case. Is the patient, whose condition is being studied, likely to recover? Is the nature of the case such that the disease from which the patient is suffering can be cured? Is the restoration, which results from medical and mental treatment, a complete one of the body and of the mind? Is the cure which results from treatment permanent? In going over our case-books and in calling to mind as far as possible this patient and that patient and every 
patient discharged, five, ten or twenty years ago, do we find that they are still living? Have they remained permanently absent from the hospital in a capable and stable frame of mind? If they have suffered from subsequent attacks of mental derangement, were their minds sound between the attacks, and what were the results of subsequent treatment in such cases?

For ten years Dr. Pliny Earle made extensive inquiries and calculations as to the curability of insanity. In summing up his work in this direction, in 1886 , he says: "The most general conclusions to be derived from the statistics included in this study are, first, that the old claim of curability in a very large majority of recent cases is not sustained, and that the failure to sustain it is more apparent and more striking than at any preceding time; and, secondly, that the percentage of reported recoveries of all cases received at the hospitals in this country continues to diminish." Although fourteen years have elapsed since Dr. Earle made this statement, and although insanity is much more skillfully treated than ever before, yet I am of the opinion that permanent mental impairment is present in a large proportion of patients discharged from our hospitals as cured.

The object of this paper is to suggest that alienists ought to persevere in their efforts to secure a scientific nomenclature for the different forms of insanity. This can be done partly by individual observation and study, partly by co-operation and a consensus of opinion. The general terms descriptive of various forms of insanity, which have been most used, are melancholia, mania and dementia. To these, names for special forms have been more recently added, such as paranoia, general paralysis, epileptic insanity and alcoholic insanity. The tendency of late has been to differentiate cases of dementia. Since there is permanent mental impairment in epilepsy, the condition may properly be called epileptic dementia. Again, general paralysis is incurable and usually progresses from bad to worse rapidly, so it is now characterized as paretic dementia. Furthermore, it is easy to group cases of mental impairment which develop late in life, and are due to failure of the faculties on account of age, as senile dementia.

There is still another method of grouping demented persons. All cases in which the first symptoms of insanity are dullness or 
weakness of mind, and when these symptoms persist as the most prominent ones, are called instances of primary dementia; and when the case is first diagnosticated as mania or melancholia or some other form of insanity, but finally the faculties are permanently lost, the condition is termed secondary dementia. Now, according to Kraepelin, cases formerly called primary dementia, and many others, should be named dementia praecox.

This is one of the processes of deterioration; the other is katatonia. Both of these conditions of weak-mindedness develop early in life, in the teens or in the twenties; seldom are they found in patients of mature years. Organic changes in the brain are believed to be present, and the mental derangement resulting therefrom varies from the slightest impairment of the mind to the most complete dementia. Kraepelin defines dementia præcox as the evolution of a simple, yet more or less well-marked, mental deterioration, having the appearance of an acute or subacute mental disturbance. There may be only a slight manifestation of mental weakness, so that neither the relatives nor the family physician regard the condition and the behavior of the patient as indicative of insanity.

A son or a daughter at home loses interest in study, drops out of school or neglects work, formerly well done, and lounges about the house. No delusions are present, the case is not considered acute nor critical, the individual gives no particular trouble, may continue to perform some simple tasks about the house and so long as fostered can dwell under the parental roof; but there is definite mental impairment which is permanent. More marked cases of dementia præcox exhibit silliness. The subjects talk to themselves more or less incoherently; they smile or laugh without provocation; they are positively indolent; they are careless about their personal appearance and sooner or later may become filthy in their habits. A contrary disposition is not infrequent, and mischievousness or viciousness may be manifested. If such persons become burdensome on account of straightened circumstances in the family, or if the old home is broken up by the death of one or both parents, such a child is sent to a hospital for the insane or to the poorhouse. Self-abuse is often assigned as the cause of the insanity in such cases.

Under the head of dementia præcox Kraepelin places the cases 
of certain beggars, tramps and dead-beats, who eke out an existence for a time, but finally land in the poorhouse.

As a rule dementia præcox begins insidiously, but the mental change may come on quite suddenly and the patient may realize that there is something serious the matter with him. Headache, dizziness, or other discomfort may not only be realized by the patient, but be complained of to and receive attention from the home physician. The patient may be restless at night and inclined to keep his bed in the daytime. Food is taken with indifference and possibly regarded with suspicion. Mild and transient hallucinations or delusions may be present. The patient may accuse himself of having bad qualities or say the neighbors are talking about him. Although he may have fair health, he may spend his time in scribbling or fill a long manuscript with nonsense. The sense of decency may be lost and neighbors declare the person to be a nuisance. At times there may be restlessness and excitement; this condition may occur at the menstrual periods or when the patient is restrained on account of disorderly conduct. Some persons who pass into a partially demented condition enjoy perfect bodily health for many years. If well managed, they make good helpers in hospitals and on poor farms. Other patients rapidly deteriorate into a state of complete helplessness. They eat in a greedy or slovenly manner, or take food sparingly or not at all; they may hold saliva in their cheeks or drool upon their clothing; they may retain their excretions or pass them involuntarily. Such persons, when neglected, may acquire most disgusting habits. Some patients soon die of tuberculosis or some other intercurrent disease. Others live many years and in classification may get mixed up with the mass of so-called cases of secondary dementia.

Cases of dementia pracox can only be differentiated by knowing the early history and by continuing observations long enough to determine the course the mental derangement will take. Kraepelin believes that dementia præcox is a very common form of mental derangement; that it usually develops early in life, between the ages of sixteen and twenty-two years; that it is more common in men than in women; that hereditary influence is well marked; that the original endowment of the patients is usually good, in some cases considerably above the average in mentality; 
that the true nature of dementia præcox is still obscure; that it may be due to imperfect structure in the brain, so that mental activity and development can not be sustained, but that more probably it is the result of positive brain disease, since it occurs before mature age has been reached and produces permanent impairment.

My understanding of Kraepelin's classification of the insane is that patients do not change from one type of insanity to another, but that the symptoms in the various stages in each case must be known before the diagnosis in doubtful cases can be made. Hence it is necessary to continue the clinical study of this subject for a long time before permanent, scientific conclusions can be reached. 